\title{
Combining Business Intelligence And Stock Market Data: A Primer For Data Analytics And Business Intelligence
}

David H. Olsen, Utah State University, USA

Pamela A. Dupin-Bryant, Utah State University, USA

\begin{abstract}
Business Intelligence (BI) has become indispensible to modern business decision-making. Organizations rely on BI to interpret the mass amounts of data circulating throughout the world. However, integration of BI into university business programs does not parallel industry demands. The purpose of this paper is to introduce an innovative business intelligence project tutorial for Information Systems (IS) education. The applied tutorial was designed to help students learn how to design and publish a report using SQL Server Reporting Services to analyze current stock market data. This tutorial exposes students to the decision-making power derived from raw data analysis and assists in development of business professionals who can maximize profitability through effective use of business intelligence.
\end{abstract}

Keywords: Business Intelligence; Business Analytics; Data Analytics; Decision Support Systems; Management Information Systems Project Tutorial; Instructional Strategies; Teaching/Learning Methods

\section{INTRODUCTION}

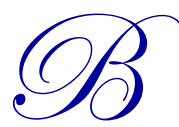

usiness Intelligence (BI) is the ability to utilize vast amounts of accumulated data to assist in making better and faster business decisions (Chaudhuri, Dayal, \& Narasayya, 2011; Fouché \& Langit, 2011). BI tools help knowledge workers to recognize trends from patterns in data and to make decisions based on those trends for the overall advantage of the organization. These Decision Support Systems (DSS) use computer power and analytical algorithms to convert immeasurable amounts of raw data into meaningful information to support enterprise-wide decision-making (Chaudhuri et al., 2011; Chen, Chiang, \& Storey, 2010; Williams, 2011). Competitive pressure in today's business world has spurred countless organizations to employ BI. Organizations from a wide range of industries have reported improvements to business processes and decisionmaking by implementing BI technologies (Chaudhuri et al., 2011; Laursen \& Thorlund, 2010; Turban, Sharda, Dursun, \& King, 2010; Turban, Sharda, \& Denlen, 2011).

The proliferation of BI in industry has increased the demand for workers with advanced analytical skills, yet the supply of skilled knowledge workers appears weak. Studies suggest an imminent shortage of analytical talent (Accenture, 2007; Manyika et al., 2011). Research by the McKinsey Global Institute forecasts a 50 to 60 percent gap between the supply and demand of people with deep expertise in data analysis, equaling 140,000 to 190,000 unfilled positions by 2018 (Manyika et al., 2011). The integration of business intelligence and analytics into university business programs has not kept pace with these market demands (Connolly, 2012; Sircar, 2009; Wixom et al., 2011).

Educators and business leaders alike suggest that business graduates, especially those in Information Systems (IS), must be exposed to BI concepts and practices during their course of study (Connolly, 2012; Conway \& Vasseur, 2009; Sircar, 2009; Wixom et al., 2011). "The landscape of BI in research and industry is vibrant today" (Chaudhuri et al., 2011, p. 98) and the enthusiasm to employ BI tools should be apparent in the education of business professionals. Business schools must alter what they teach in order to prepare qualified graduates in the area of business intelligence and analytics (Connolly, 2012; Conway \& Vasseur, 2009; Sircar, 2009; Watson, 2008; 
Wixom et al., 2011). The integration of BI into business curriculum is gaining some ground with various aspects of BI being taught in many business schools. However, there is still more work to be done to develop pedagogy to support BI curricular initiatives (Wixom et al., 2011). Wixom and her colleagues recommend providing opportunities for students to solve meaningful problems framed in current business contexts; they also encourage universities to seek ways to share BI teaching materials (2011).

The purpose of this paper is to share an innovative business intelligence project tutorial for information systems education. This project tutorial is based on a well-respected theory of learning and grounded in current BI, database, and financial literature. The applied tutorial was designed to help students learn how to design and publish a report using SQL Server Reporting Services to analyze current stock market data. This tutorial exposes students to the decision-making power derived from raw data analysis and seeks to serve as a catalyst for students preparing to become business professionals who can maximize profitability through effective use of BI.

Four objectives provide a structure for this paper: 1) highlight relevant literature pertaining to BI in both business and educational environments, 2) outline the methods employed, 3) describe, in detail, the steps involved in the BI project tutorial, and 4) provide concluding remarks and suggestions for future research and practice. This paper seeks to demonstrate the importance of integrating business intelligence learning objectives into university business curricula. The project tutorial identified in this paper should prove helpful to information systems educators who seek to provide a rigorous, practical, and relevant BI experience in their courses.

\section{LITERATURE REVIEW}

Business intelligence (BI) has been used as "an umbrella term to describe concepts and methods to improve business decision-making by using fact-based support systems" including underlying tools, architectures, applications, databases, and methodologies (Chen et al., 2010, p. 201). Analytics is a component of BI that "provides the data analysis techniques used to deliver value from decision support data" (Wixom et al., 2011, p. 300). However, consistent with current practice the terms business intelligence (BI) and business analytics (BA) are often used interchangeably (Sircar, 2009; Wixom et al., 2011); BI being the preferred term used by information technology professionals and BA more often used by the broader business community (Sircar, 2009). BI is used in this paper as an overarching term to describe BI/BA objectives that provide business professionals the ability to easily access, interact with, manipulate, and transform large amounts of diverse data (Chen et al., 2010; Turban, et al., 2011).

During the past two decades, BI has enjoyed rapid growth in industry (both in adoption of technologies and number of products/services offered) and the growth is projected to continue well into the next decade (Chaudhuri et al., 2011; Manyika et al., 2011). More Chief Information Officers (CIOs) are placing BI at the top of their agendas; more companies are investing in data collection, extraction, and analysis; and more organizations (such as Accenture, Deloitte, and IBM) are opening new analytics centers (Chen et al., 2010; IBM, 2009; Luftman \& BenZvi, 2010; Pettey \& Goasduff, 2011; Turban et al., 2010). Competitive pressure in today's business world has prompted myriad organizations to employ BI. Organizations from a wide range of industries have reported obvious improvement to business processes and decision-making by implementing BI technologies (Chaudhuri et al., 2011; Laursen \& Thorlund, 2010; Turban et al., 2010; Turban et al., 2011). Companies such as Northwestern Mutual Life, Marriott International, McCormick \& Company, Pinnacle Food Group, and Lockheed Martin have all integrated BI into their business strategy in order to compete and thrive in the current marketplace (Williams, 2011). Laursen and Thorlund (2010) suggest "by now, it's an acknowledged fact that all the money that is invested is returned manyfold when BA [and BI] solutions are implemented and executed in the right way" (p. xiv).

A significant constraint in realizing the value from BI will be a shortage of talent employees. The proliferation of BI in industry has spurred the demand for knowledge workers with advanced analytical skills yet the supply of workers appears weak. Studies suggest an imminent shortage of analytical talent (Accenture, 2007; Manyika et al., 2011). Research by the McKinsey Global Institute forecasts a 50 to 60 percent gap between the supply and demand of people with deep expertise in data analysis, equaling 140,000 to 190,000 unfilled positions by 2018 (Manyika et al., 2011). Furthermore, in the United States alone a projected 1.5 million managers and analysts 
will lack the requisite skills to understand and make decisions based on the analysis of vast amounts of data (Manyika, et al., 2011).

The integration of business intelligence and analytics into university business programs has not kept pace with these growing market demands (Connolly, 2012; Sircar, 2009; Wixom et al., 2011). Connolly (2012) suggests "BI is about quickly making sense of the vast amounts of data collected about all dimensions of a business, and then making sound decisions that will generate value for the company. For business schools, it's also a big opportunity, one that is, by and large, being missed" (para. 1). A recent BI Congress and companion surveys were conducted to evaluate the state of BI in academia (Wixom et al., 2011). Results suggest "business intelligence is in high demand in industry and that aspects of BI are being taught in many business schools...the results also show a mismatch at both the undergraduate and graduate levels between what our students learn and what our students need to know" (Wixom et al., 2011, p. 308).

Many business leaders and educators argue that business graduates must be exposed to BI concepts and practices during their course of study (Connolly, 2012; Conway \& Vasseur, 2009; Sircar, 2009; Wixom et al., 2011). BI was recently incorporated into IS 2010 curriculum guidelines for undergraduate degree programs; BI is listed as an important topic within the Data and Information Management knowledge area (Topi et al., 2010). Although a step in the right direction, this is not sufficient to create BI employment ready graduates (Wixom et al., 2011). Business schools must alter what they teach in order to prepare qualified graduates in the area of business intelligence and analytics (Connolly, 2012; Conway \& Vasseur, 2009; Sircar, 2009; Watson, 2008; Wixom et al., 2011).

Given the increasing emphasis on BI in most organizations, successful IS graduates must be able to understand and apply BI principles. Sircar (2009) argues one reason BI has been overlooked in the business curriculum is the continuing trend of faculty to focus on rigor at the expense of practical relevance. Business faculty should break this trend and find creative methods to integrate rigorous and relevant BI learning objectives into university business courses. Wixom and her colleagues recommend providing opportunities for students to solve meaningful problems framed in current business contexts and to "find ways to share teaching materials" (2011, p. 308).

\section{METHODS}

The business intelligence project tutorial outlined in this paper was designed to expose students to the decision-making power derived from raw data analysis. This applied tutorial was designed as a stand-alone activity that can be employed in any university database course to help students apply the business intelligence tools offered in the Microsoft SQL Server Development Environment. Students learn how to design and publish a report using SQL Server Reporting Services (SSRS) to analyze current stock market data. The tutorial utilizes stock market statistical data available on the web to allow students to determine whether or not a given stock should be bought or sold. The project tutorial utilizes a 35-day moving average, but any moving average of reasonable length could be used. The exact data set used in this tutorial may not be readily available; however, any comparable data may be substituted into the framework provided to ensure students are introduced to fundamentals of raw data analysis.

The project tutorial was originally designed to be taught over a two week period (i.e., two 75-minute class sessions) but could easily be adapted to shorter or longer time periods. Students will ideally have prior knowledge of conventional database principles. The tutorial has been tested and successfully applied in various upper division university database courses. However, information systems educators should modify and apply this project tutorial based on the needs of their students, their individual teaching preferences, and the course learning objectives.

The content of the BI project tutorial utilizes Gagne's Nine Events of Instruction as a learning framework (Gagné, Briggs, \& Wager, 1992). Gagne's Nine Events of Instruction is a well respected, systematic approach to teaching and is often employed as a tool for training and developing instructional strategies in business and technology-related fields (IEEE, 2011; Liu, 2008; Reisslein, Seeling, \& Reisslein, 2005; Zhu \& St. Amant, 2010). The events of instruction include: 1) Gain Attention, 2) Inform Learner of Objectives, 3) Stimulate Recall of Prior Learning, 4) Present Stimulus Material, 5) Provide Learner Guidance, 6) Elicit Performance, 7) Provide Feedback, 
8) Assess Performance, and 9) Enhance Retention and Transfer. The instructional flow of this BI project tutorial follows Gagne's nine events. The alignment of the project tutorial with Gagne's Nine Events of Instruction provides an educational environment in which learning and retention are enhanced.

\section{Project Tutorial Description}

Following Gagne's Nine Events of Instruction (Gagné et al., 1992), this business intelligence project tutorial design includes a presentation of the learning objectives, the learning content, and practice activities with feedback and review of the learning content. All the components of the project tutorial are instructionally aligned with the learning objectives. The following section outlines each of the events of instruction employed in the BI project tutorial.

\section{Gain Attention}

The instructor should conduct a discussion about business intelligence, data analytics, and the powerful tools used to convert boundless data into meaningful information used for business decision-making. Content for this discussion can be found online, in course textbooks, and/or from myriad references identified in this manuscript. Current and interesting material related to the topic should be used (as per the instructor's preference) to gain student attention. Table 1 highlights several BI resources that may prove useful in preparation.

Table 1: Business Intelligence Resources

\begin{tabular}{|l|l|l|l|}
\hline Title & Author(s) & Year & Publisher \\
\hline Microsoft SQL Server 2012 Reporting Services & Larson & 2012 & McGraw-Hill \\
\hline Foundations of SQL Server 2008 R2 Business Intelligence & Fouché \& Langit & 2011 & Apress \\
\hline The Microsoft Data Warehouse ToolKit & Mundy, et al. & 2011 & Wiley \& Sons \\
\hline Microsoft SQL Server Reporting Services Recipes & Turley \& Bruckner & 2010 & Wrox \\
\hline Knight's Microsoft Business Intelligence 24-Hour Trainer & Knight, et al. & 2010 & Wrox \\
\hline
\end{tabular}

Inform Learner of Objectives

After the instructor has gained student attention, the instructor should introduce the learning objectives. The learning objectives should be highlighted in an easy to read format (e.g., slide show) and also posted on the course Learning Management System (LMS) for easy retrieval and student access.

Students should be informed of the following objectives:

- Understand the need for business intelligence given ever-increasing amounts of data

- $\quad$ Describe the value of data analytics to modern business decision-makers

- Demonstrate effective use of the business intelligence tools offered in the Microsoft SQL Server Development Environment to provide meaningful analysis requirement).

Figure 1 provides an introduction to the tutorial along with the objectives and project scenario (business

Introduction and Objectives

This tutorial will guide you through the process of designing and publishing a report using SQL Server Reporting Services (SSRS) to display historical stock market data grouped by industry, tickersymbol, time, and to display buy/sell indicators based on a 35-day moving average analysis. Upon completion of this tutorial you should be able to describe the value of data analytics to modern business decision-makers and effectively use an analytical tool to provide meaningful analysis.

\section{Business Requirement}

Assume you are a Business Intelligence Developer and your manager requests a report that will show historical stock market prices organized by industry, year, quarter, month, and day. Specifically, the manager would like to see buy/sell/hold indicators for each stock based on their current 35-day moving average.

\section{Figure 1: Project Tutorial Introduction, Objectives, and Requirements}




\section{Stimulate Recall of Prior Learning}

After the learner is informed of the objectives, the instructor should engage in a discussion related to prior learning. As previously noted, this project tutorial assumes students have prior knowledge of conventional relational database principles. The instructor and students should each open the database that will be used in the project tutorial. Students should be asked to recall and explain what they know about database design. The instructor should stimulate recall of prior learning by asking students questions about tables, relationships, keys, data types, and attributes as they pertain to the StockData Table and CalendarBasic Table (see Figure 2). To engage all students, the use of a computer response system (e.g., i>clickers) is a good method for stimulating recall of prior learning.

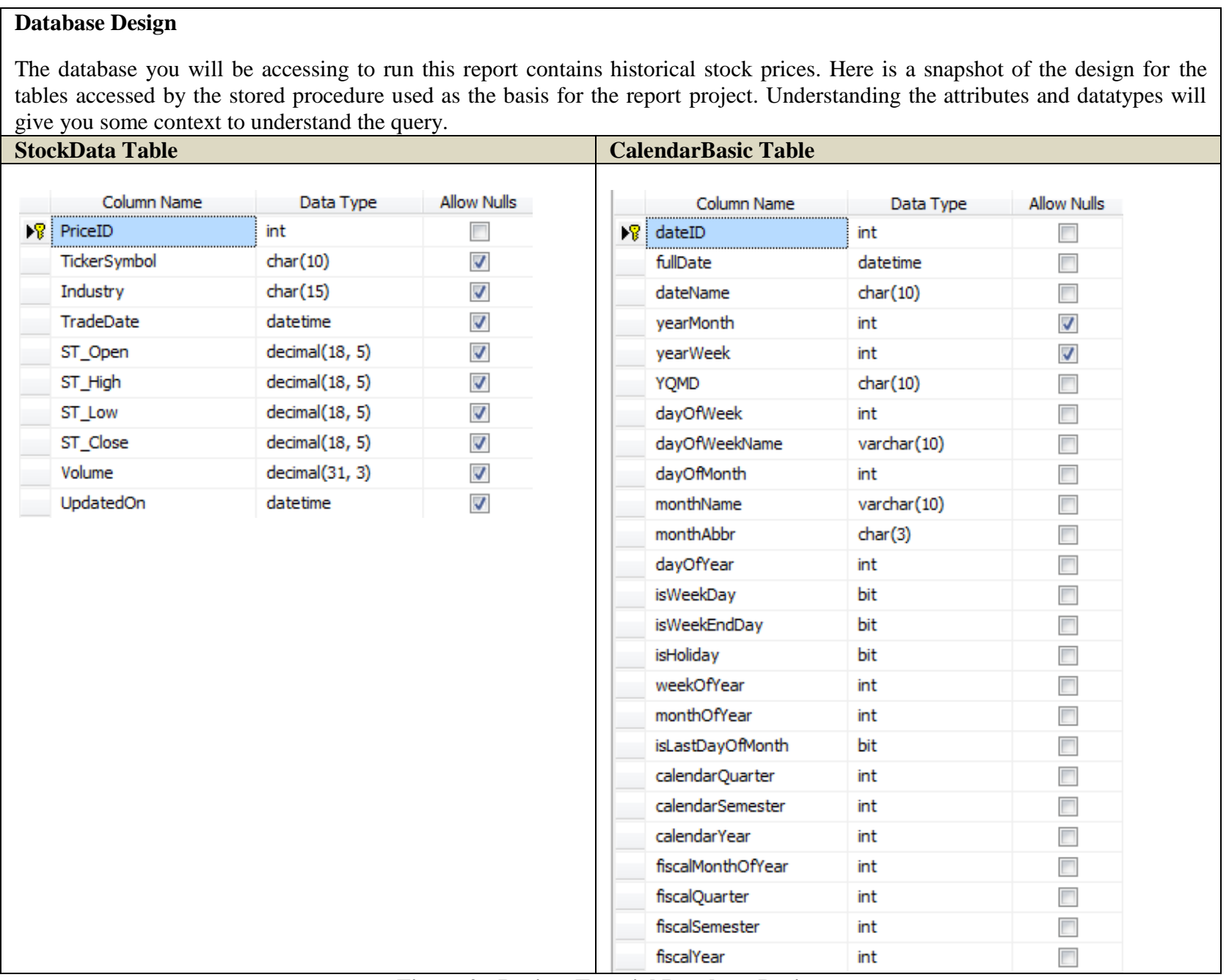

Figure 2: Project Tutorial Database Design

\section{Present Stimulus Material}

Daily closing stock values are often compared to a multiple day moving average price value of that stock. Moving averages of stock prices are often used as indicators for the purchase or sale of stocks on the market (Brock, Lakonishok, \& LeBaron, 1992; ChartSchool, 2012). Since this tutorial requires students to determine whether or not a given stock should be bought or sold based on raw stock market statistical data, the instructor should provide stimulus material relative to moving charts. Students should be asked to read, explore, and interact with the content/live charts related to simple and exponential moving charts at StockCharts.com - ChartSchool. Figure 3 highlights an activity which stimulates discussion of the SQL Stored Procedure (designed to calculate the 35-day moving average) prior to building the report. 


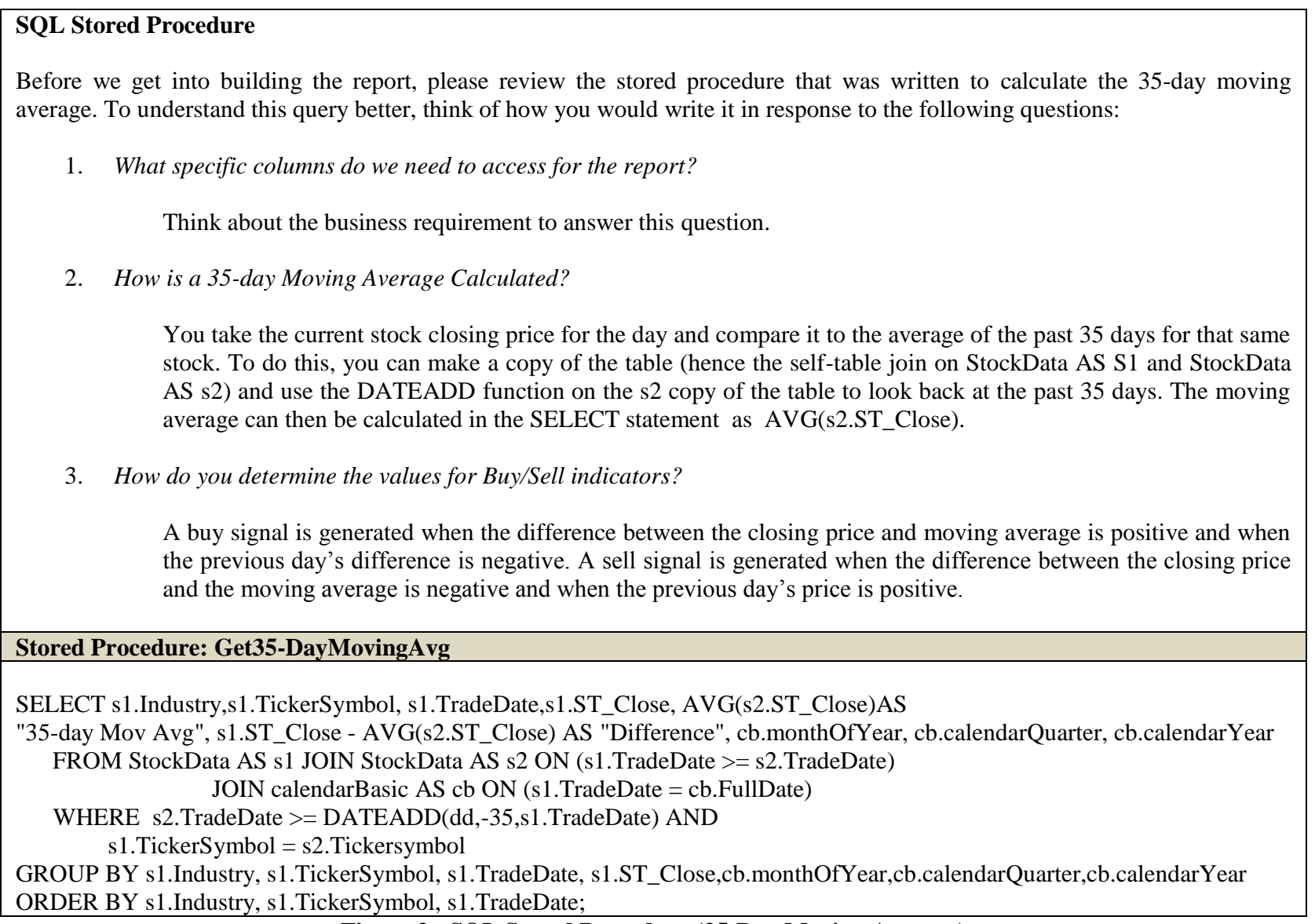

Figure 3: SQL Stored Procedure (35-Day Moving Average)

\section{Provide Learner Guidance}

The process of building a report should be displayed on an overhead projector, providing students with both audio and visual assistance. In addition, the slides (containing screenshots) and a video created using screen recording software (e.g., Camtasia Studio or CamStudio) should be posted on the course learning management system to provide additional learner guidance.

\section{Elicit Performance}

Once the instructor has provided guidance by demonstrating the process of building a report to assist decision-making, students should then complete the tutorial steps to practice the skills and new knowledge using realistic data (see Figures 4-11). Students should perform each of the following steps: 1) create a new project, 2) select a data source, 3) add a new report, 4) design the query, 5) design the report type, 6) design the table, 7) choose the table layout, 8) customize the report, 9) change aggregate type, 10) customize the table layout, 11) add report items, 12) define gauge data and indicator properties, 13) define sparkline chart data, and 14) preview the report. Figures 4-11 highlight each of these detailed steps divided into eight parts. The steps can be completed all at once or in parts, as per the discretion of the instructor in accordance with the course time frame. 


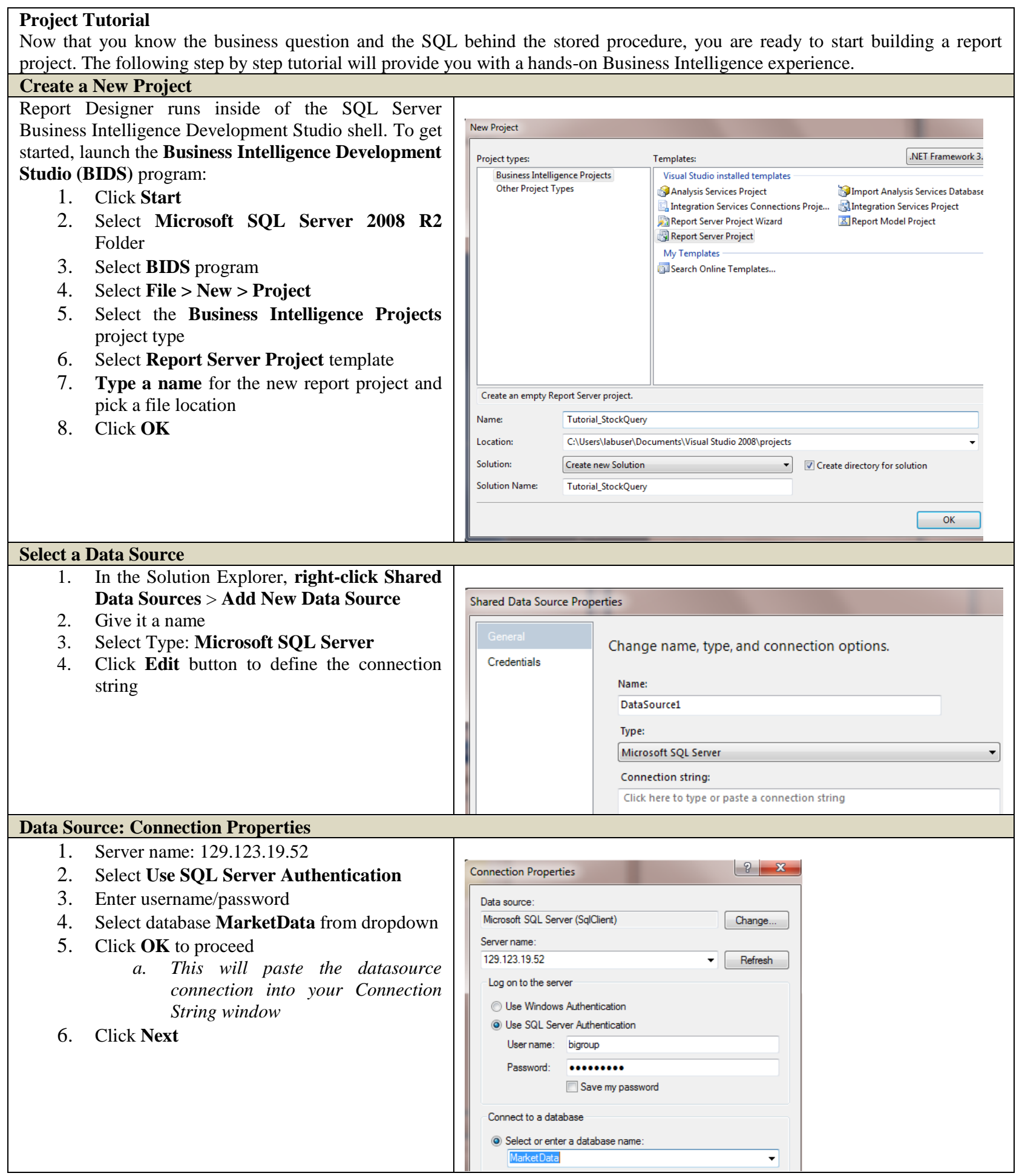

Figure 4: Project Tutorial Steps - Part A 


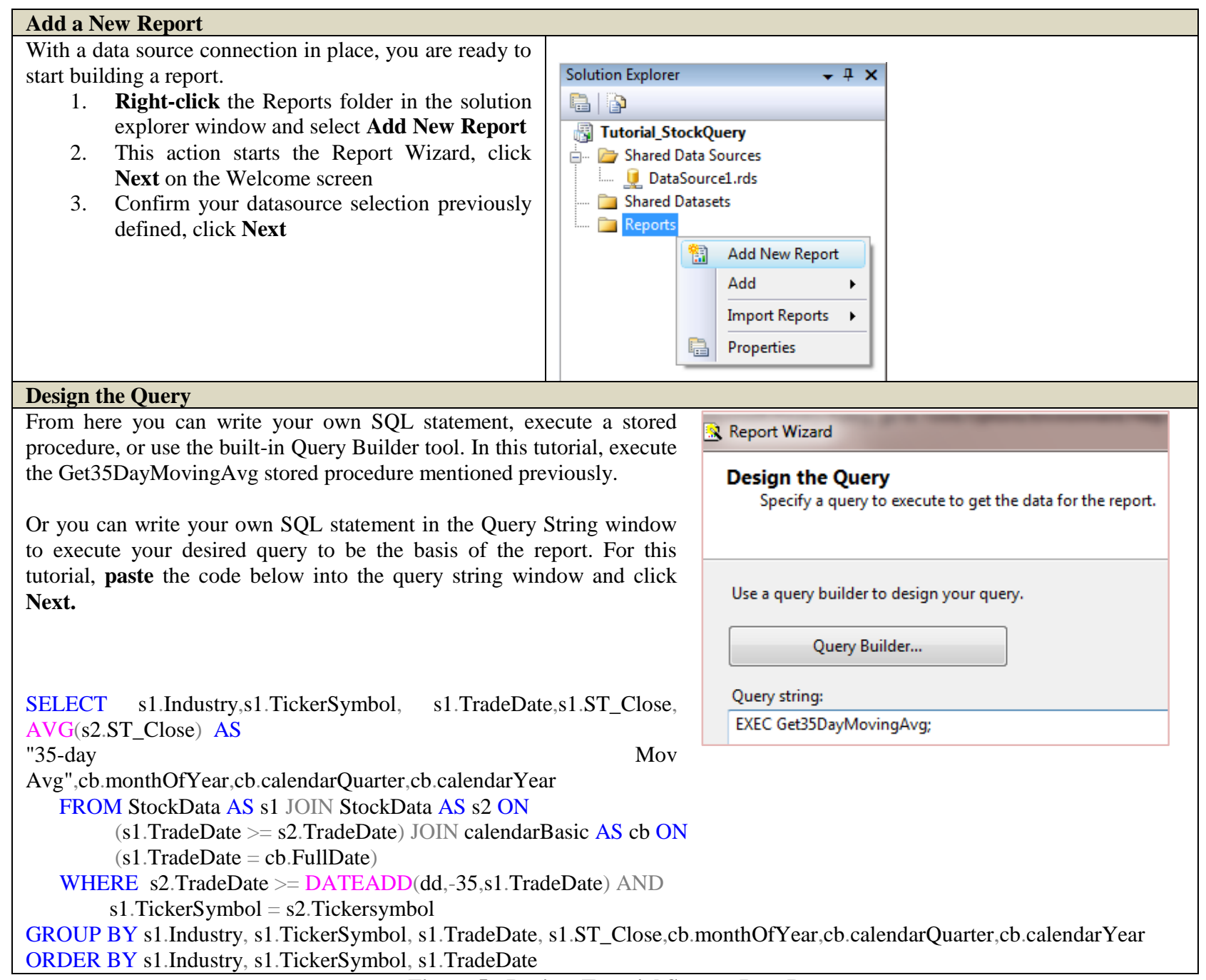

Figure 5: Project Tutorial Steps - Part B 


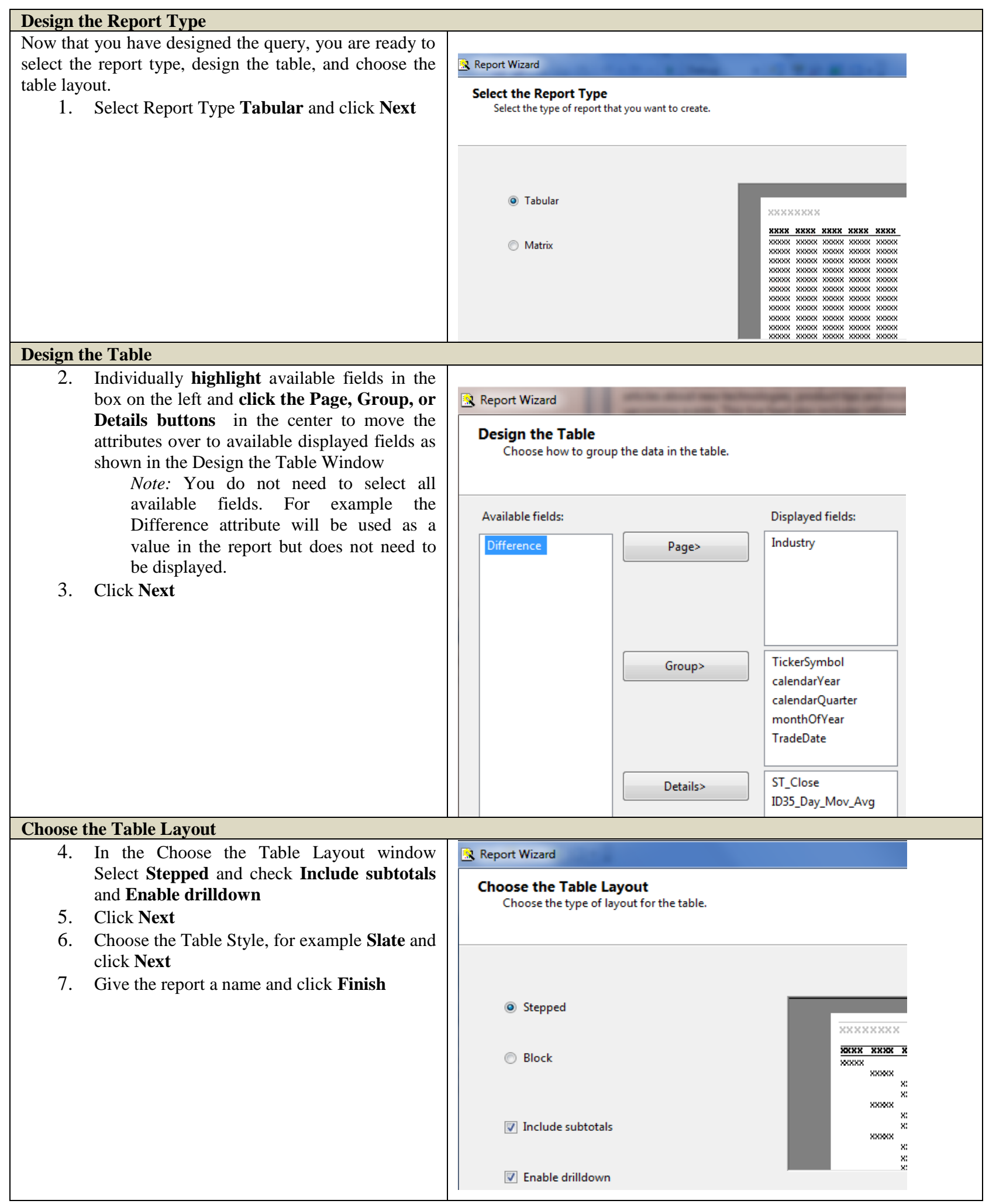

Figure 6: Project Tutorial Steps - Part C 


\begin{tabular}{|c|c|c|c|c|c|c|c|}
\hline \multicolumn{8}{|c|}{ Customize the Report } \\
\hline \multicolumn{8}{|c|}{$\begin{array}{l}\text { Now that you have established a data source, designed a query, and specified the layout and style of the report, you can view the } \\
\text { Report Design and make desired customizations. }\end{array}$} \\
\hline Ticker Svm & Calendar Ye & Calendar Ou & & ST Close & \\
\hline \multirow[t]{6}{*}{ [TickerSvmbol } & & & \multicolumn{2}{|l|}{ month of $\mathrm{Y}$} & [Sum(ST Closı|[Sum(ID35 Da & \multicolumn{2}{|c|}{ IDSum(ID35 Da } \\
\hline & [calendarYeaı| & & \multicolumn{2}{|l|}{ - } & \multicolumn{3}{|c|}{ [Sum(ST_Closı][Sum(ID35_De } \\
\hline & & [calendarQuaı & & & \multicolumn{3}{|c|}{ [Sum(ST_Closı [Sum(ID35_De } \\
\hline & & & \multicolumn{2}{|l|}{ [monthofYear } & \multicolumn{3}{|c|}{ [Sum(ST_Closı [Sum(ID35_De } \\
\hline & & & 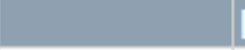 & [TradeDate] & \multicolumn{3}{|c|}{ [Sum(ST_Clos! [Sum(ID35_De } \\
\hline & & & & & \multicolumn{3}{|c|}{ 「ID35 Day Mov } \\
\hline \multicolumn{8}{|c|}{ Change Aggregate Type from Sum to Average } \\
\hline \multirow{8}{*}{\multicolumn{3}{|c|}{ 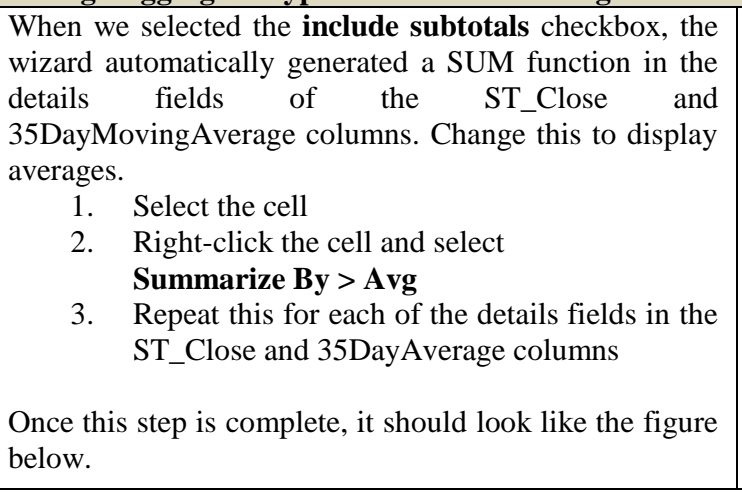 }} & \multirow{8}{*}{$\begin{array}{l}\text { ST Clost } \\
\text { [Avg(ST_Clo: } \\
\text { [Sum(ST_Clo } \\
\text { [Sum(ST_Clo } \\
\text { [Sum(ST_Clo } \\
\text { [Sum(ST_Clo } \\
\text { 「ST Close] } \\
\end{array}$} & & & \\
\hline & & & & & & & \\
\hline & & & & \multicolumn{2}{|c|}{ e ID35 Dav M } & & \\
\hline & & & & \multicolumn{2}{|c|}{ \& Cut } & & \\
\hline & & & & los 1 . Paste & & & \\
\hline & & & & Convert & To Text & & \\
\hline & & & & Summa & rize By & • & Sum \\
\hline & & & & Expressi & & & Avg \\
\hline Ticker Svm & calendar Ye & calendar Ou & month of $\mathbf{Y}$ & Trade Date & ST Close & ID35 & Dav M \\
\hline ITickerSvmbol & & & & & [Ava(ST Clost & [Avq(I & ID35 Da \\
\hline & [calendarYeaı & & & & [Avg(ST_Clost & [Avg(I & ID35_Da \\
\hline & & [calendarQuaı & & & [Avg(ST_Close & [Avg(1) & ID35_Da \\
\hline & & & [monthofYear & & [Avg(ST_Clost] & [Avg(I & ID35_De \\
\hline & & & & [TradeDate] & [Sum(ST_Closı & [Sum(] & ID35_De \\
\hline & & & & & [ST Close] & 「ID35 $\mathrm{c}$ & Day Mov \\
\hline
\end{tabular}

Figure 7: Project Tutorial Steps - Part D 


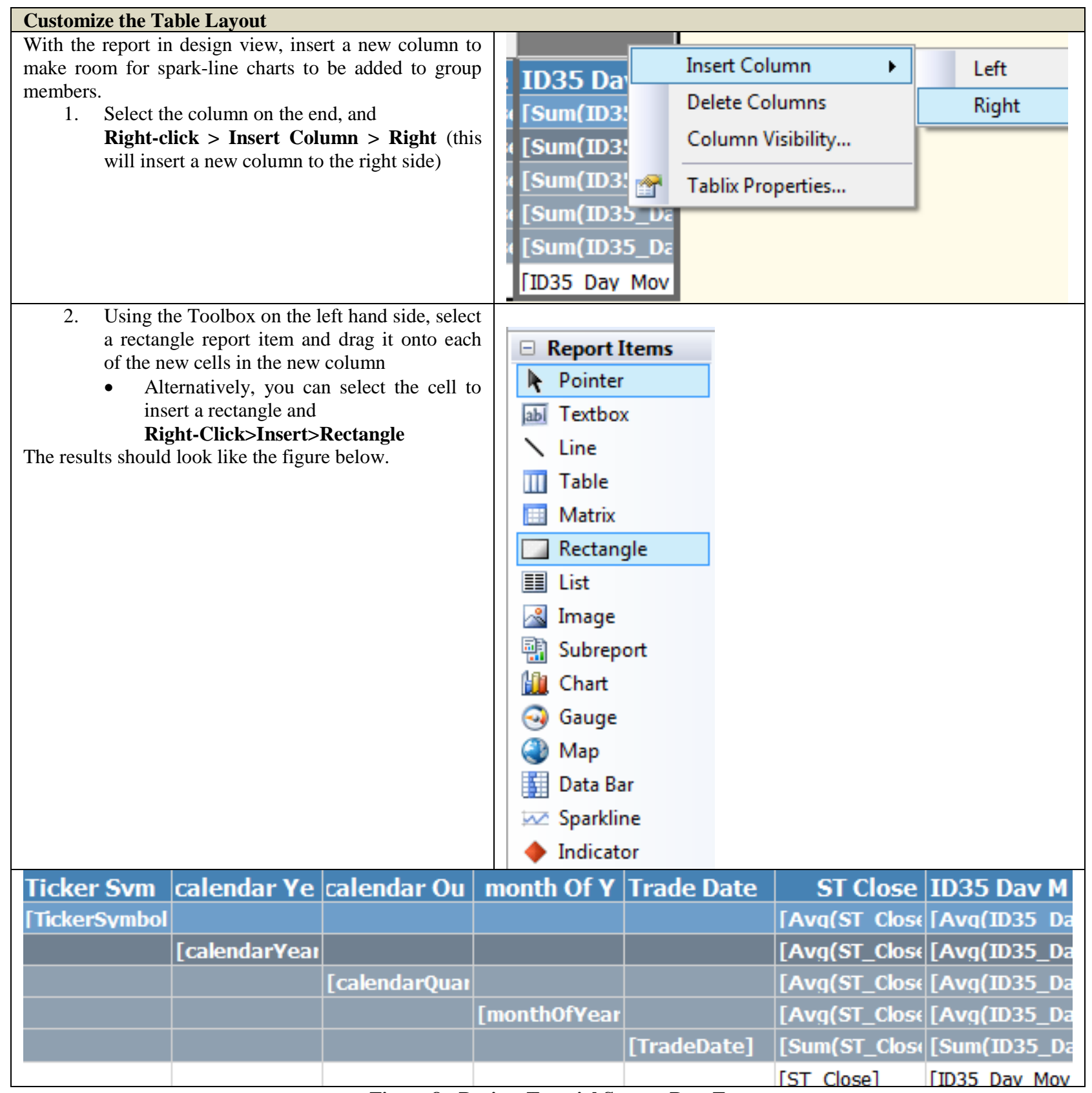

Figure 8: Project Tutorial Steps - Part E 


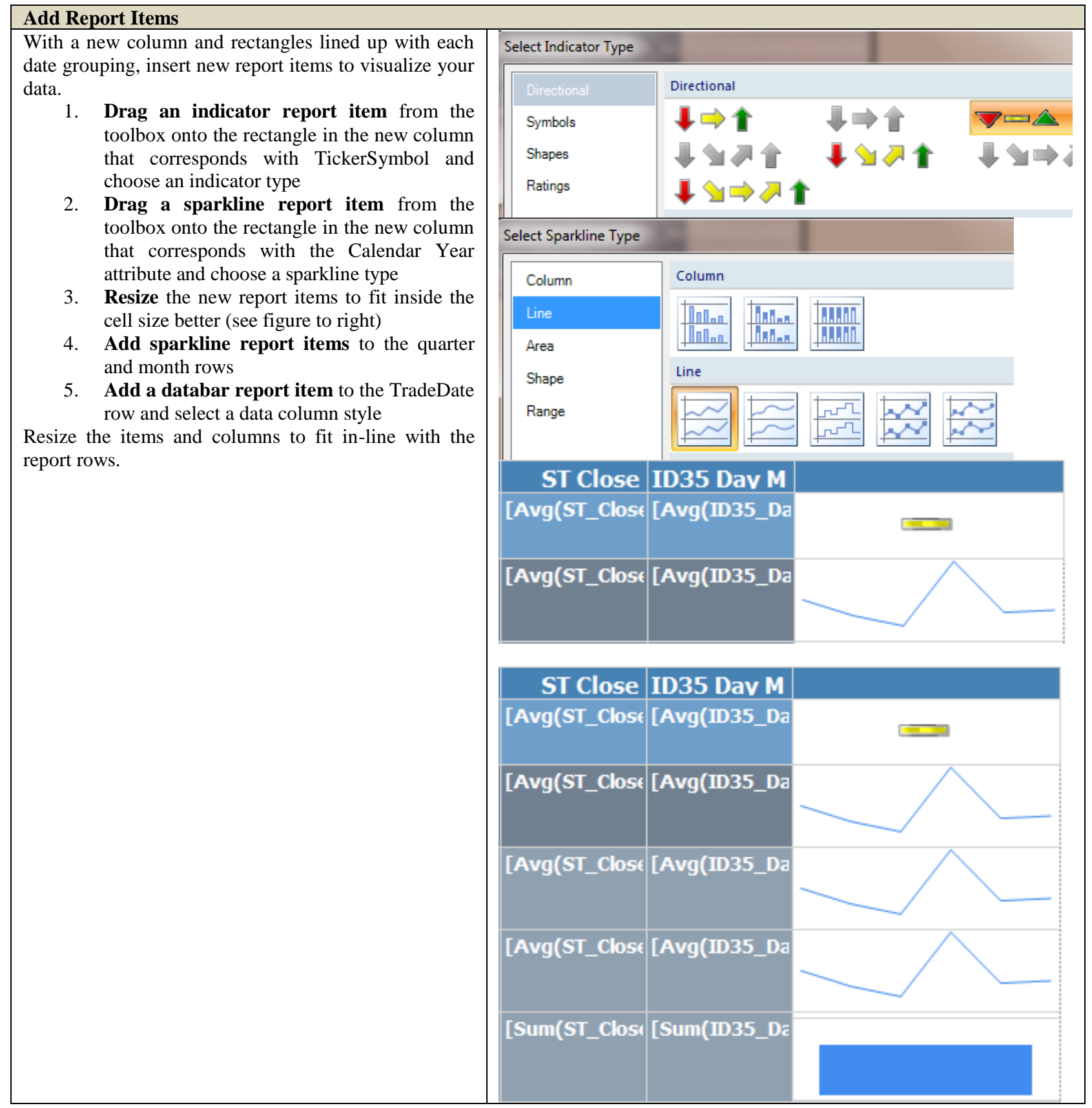

Figure 9: Project Tutorial Steps - Part F 


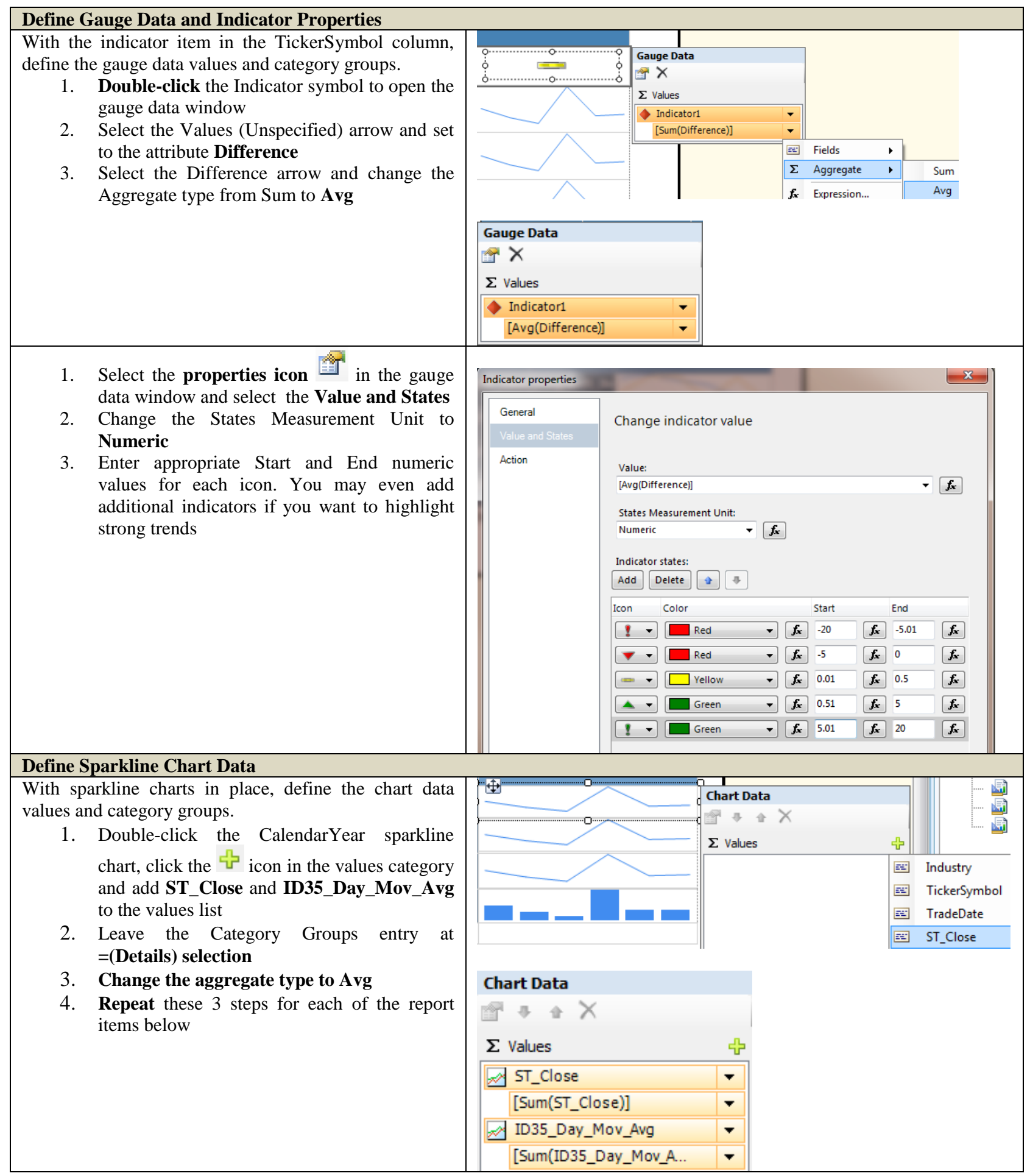

Figure 10: Project Tutorial Steps - Part G 


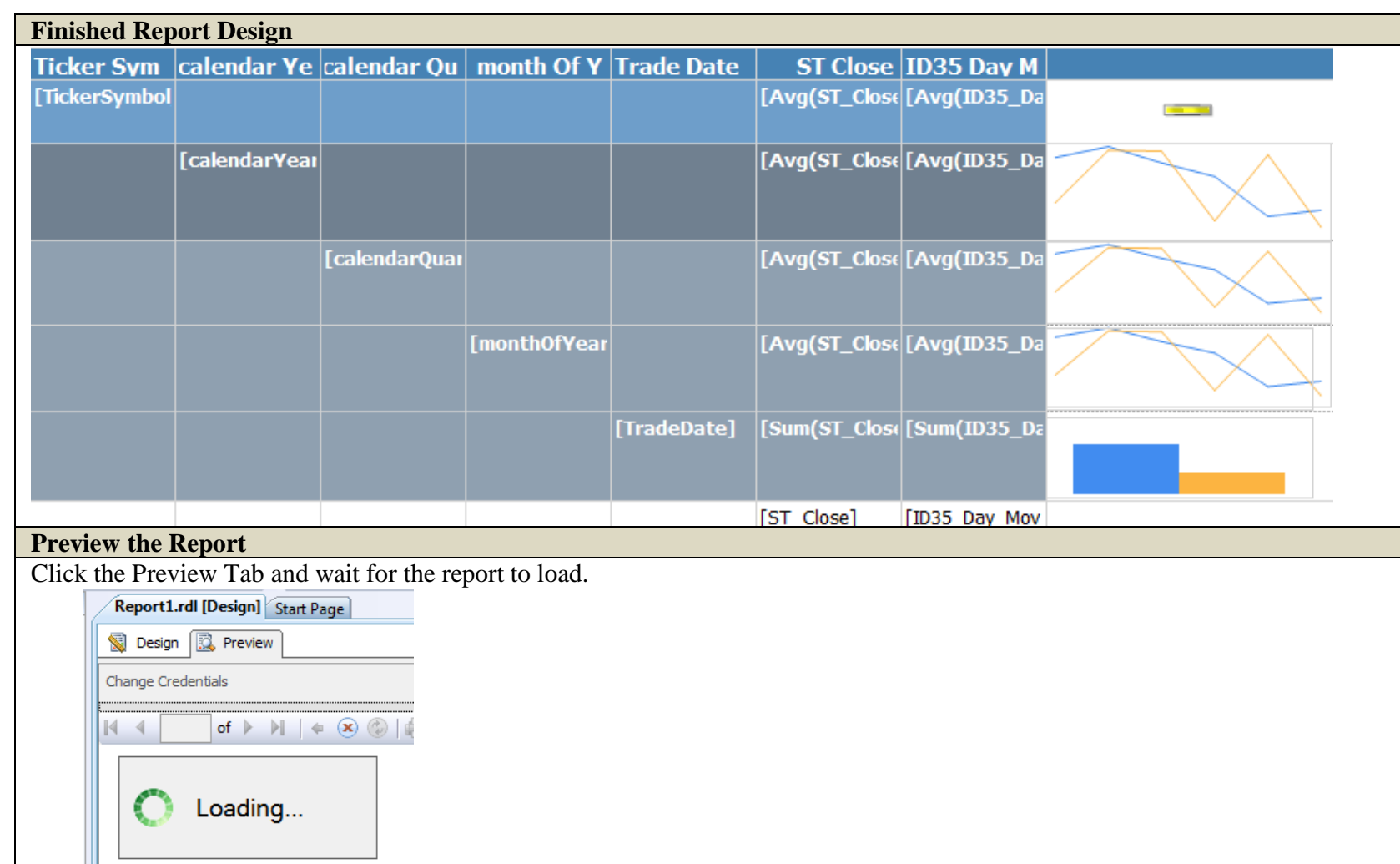

When loading is complete you should see a preview with active drill-down capability and charts displaying data for as you designed.

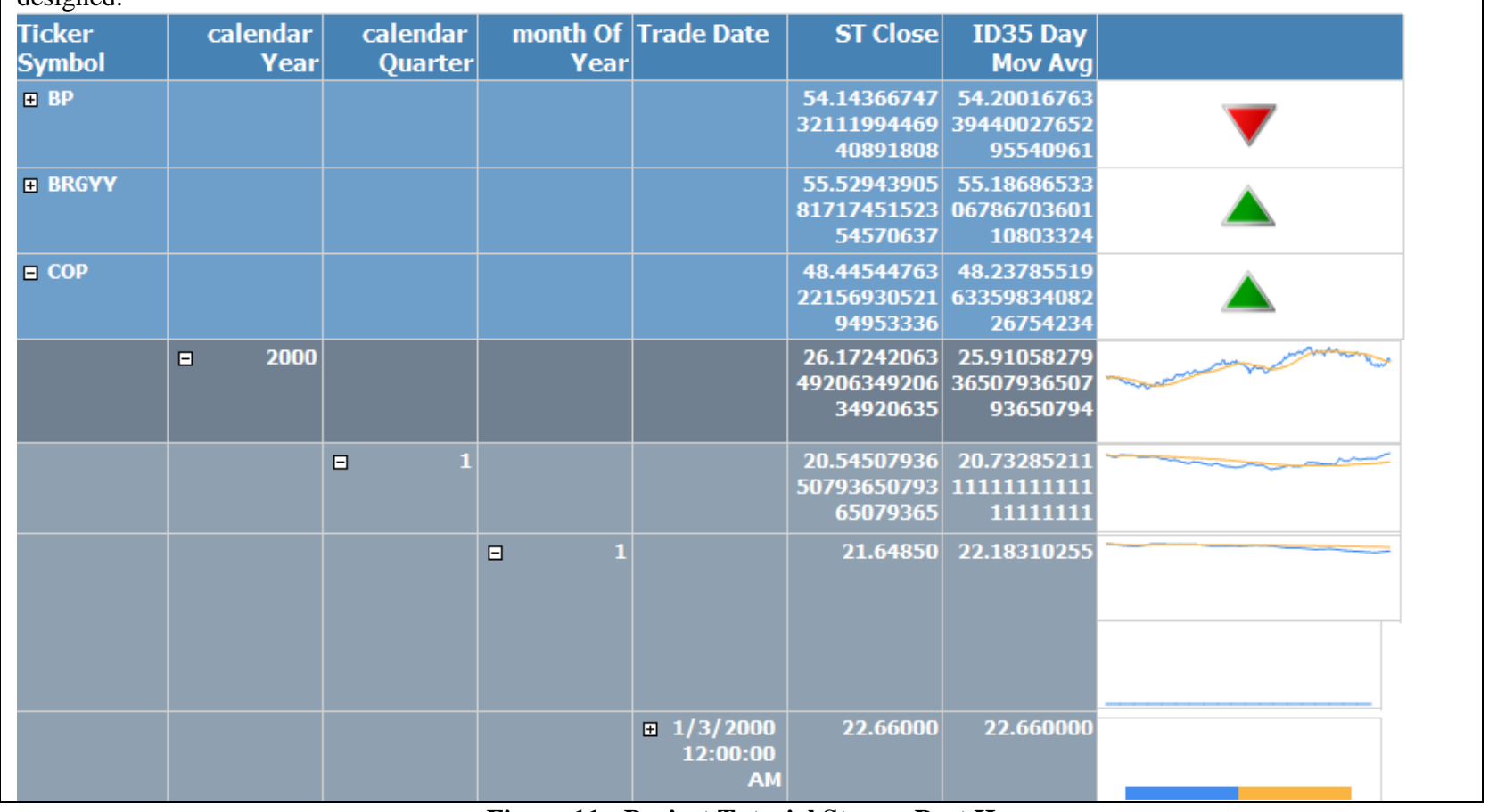

Figure 11: Project Tutorial Steps - Part H 


\section{Provide Feedback}

While students are working on the steps in the project tutorial, the instructor should provide specific and immediate feedback relative to their individual performance. The instructor should be available to answer any questions and guide students throughout the process.

\section{Assess Performance}

Once the BI project tutorial is complete, the results are evaluated by: (a) the instructor, (b) the student (self-assessment), and (c) a peer. A detailed rubric should be given to the students to help with the assessment process. This triangulated assessment procedure is designed to reinforce student knowledge. Given the feedback, each student should be required to make the necessary corrections and resubmit.

\section{Enhance Retention Transfer}

In line with the original scenario of the project tutorial (business requirement), students are then asked to make modifications to their original report. For this activity students are not provided with step by step instructions, however they are able to use any available resource to complete the modifications. This activity is designed to help students apply the knowledge they have acquired to this point. The instructor should be available to answer questions and help students with the revisions.

\section{CONCLUSION}

Business Intelligence has become indispensible to modern business decision-making. Organizations rely on BI to interpret the mass amounts of data circulating throughout the world. IS students must become familiar with basic BI principles and implementations if they are to succeed in the modern world. Current institutions of higher education, however, are still lacking in the application of both BI tools and principles in business classrooms.

This paper outlined an innovative BI project tutorial for information systems education. The applied tutorial was designed to help students learn how to design and publish a report using SQL Server Reporting Services to analyze current stock market data. The tutorial exposes students to the decision-making power derived from raw data analysis and assists in development of business professionals who can maximize profitability through effective use of BI. The steps outlined in this paper may prove helpful for educators who seek to provide a practical and relevant BI experience for students. Continued research and practice in this area is warranted to prepare students to make sound decisions based on the vast amount of data collected by modern corporations. Educators are encouraged to explore other creative approaches for introducing BI into the curriculum.

\section{AUTHOR INFORMATION}

David Olsen is the Management Information Systems Department Head at Utah State University. He received his Ph.D. in Management Information Systems from The University of Arizona in 1993 and taught at The University of Akron accounting department in accounting information systems for five years. Dr. Olsen joined the MIS department at Utah State University in 1998 and teaches primarily in the database area as well as the MBA strategy and management course. His research interests include database concurrency control, accounting information systems, the integration of SQL, XML and XBRL, and database modeling. His research has been published in journals such as Communications of the ACM, Issues in Accounting Education, and the Journal of Database Management. Dr. Olsen is happiest with regards to the teaching awards he has received. E-mail: david.olsen@usu.edu (Corresponding author)

Pam Dupin-Bryant is an Associate Professor of Management Information Systems at Utah State University. She received her M.S. degree in Business Information Systems at USU and her Ph.D. in Education - Adult Learning and Technology from the University of Wyoming. Her research and scholarly writings have focused primarily on information systems pedagogy, e-learning/distance education, and business ethics. Her primary teaching activities include web design/development, business applications programming, and principles of MIS. During her 19 years at 
the USU Tooele Regional Campus, Dr. Dupin-Bryant has employed a wide variety of delivery methods and educational strategies to facilitate student learning. E-mail: pam.dupin-bryant@usu.edu

\section{REFERENCES}

1. Accenture. (2007). Cultivating high performance through information management. Retrieved from http://www.meritalk.com/uploads_legacy/whitepapers/AIMSCIOSurvey.pdf

2. Brock, W., Lakonishok, J., \& LeBaron, B. (1992). Simple technical trading rules and the stochastic properties of stock returns. The Journal of Finance, 47(5), 1731-1764.

3. ChartSchool. (2012). Moving averages - simple and exponential . Retrieved from http://stockcharts.com/school/doku.php?id=chart_school:technical_indicators:moving averages

4. Chaudhuri, S., Dayal, U., \& Narasayya, V. (2011). An overview of business intelligence technology. Communications of the ACM, 54(8), 88-98.

5. Chen, H., Chiang, R. H. L, \& Storey, V. C. (2010). Business intelligence research. MIS Quarterly, 34(1), 201-203.

6. Connolly, D. (2012). Why b-schools should teach business intelligence. Bloomberg Businessweek. Retrieved from http://www.businessweek.com/articles/2012-04-23/why-b-schools-should-teach-businessintelligence

7. Conway, M., \& Vasseur, G. (2009). The new imperative for business schools. Business Intelligence Journal, 14(3), 13-17.

8. Fouché, G., \& Langit, L. (2011). Foundations of SQL server 2008 R2 business intelligence (2 ${ }^{\text {nd }}$ ed.). New York, NY: Apress.

9. Gagné, R. M., Briggs, L. J., \& Wager, W. W. (1992). Principles of instructional design (4th ed.). Belmont, CA: Wadsworth/Thomson.

10. IBM. (2009). The new voice of the CIO: Insights from the global chief information officer study. Retrieved from http://www-304.ibm.com/businesscenter/cpe/download0/183490/MM_CIO_Study.pdf

11. IEEE (2011). Gagne's nine events. Retrieved from https://www.ieee.org/publications_standards/publications/subscriptions/prod/mdl/gagnes_nine events.html

12. Laursen, G. H. N., \& Thorlund, J. (2010). Business analytics for managers: Take business intelligence beyond reporting. Hoboken, NJ: John Wiley and Sons.

13. Liu, G. (2008). Innovating research topics in learning technology: Where are the new blue oceans? British Journal of Educational Technology, 39(4), 738-747.

14. Luftman, J., \& Ben-Zvi, T. (2010). Key issues for IT executives 2009: Difficult economy's impact on IT. MIS Quarterly Executive, 9(1), 49-59.

15. Manyika, J., Chui, M., Brown, B., Bughin, J., Dobbs, R., Roxburgh, C., \& Hung Byers, A. (2011). Big data: The next frontier for innovation, competition, and productivity, McKinsey Global Institute: McKinsey and Company. Retrieved from

http://www.mckinsey.com/Insights/MGI/Research/Technology_and_Innovation/Big_data_The_next_fronti er for innovation

16. Pettey, C., \& Goasduff, L. (2011). Gartner executive programs worldwide survey of more than 2,000 CIOs identifies cloud computer as top technology priority for CIOs in 2011. Stamford, CT: Gartner Research.

17. Reisslein, J., Seeling, P., \& Reisslein, M. (2005). Computer-based instruction on multimedia networking fundamentals: Equational versus graphical representation. IEEE Transactions on Education, 48(3), 438447.

18. Sircar, S. (2009). Business intelligence in the business curriculum. Communications of the Association for Information Systems, 24(17), 289-302.

19. Topi, H., Valacich, J., Wright, R., Kaiser, K., Nunamaker, J., Sipior, J., \& de Vreede, G. (2010). IS 2010: Curriculum guidelines for undergraduate degree programs in information systems. Communications of the Association for Information Systems, 26(18), 359-428.

20. Turban, E., Sharda, R., \& Denlen, D. (2011). Decision support and business intelligence systems $\left(9^{\text {th }}\right.$ ed.). Upper Saddle River, NJ: Pearson Prentice Hall.

21. Turban, E., Sharda, R., Dursun, D., \& King, D. (2010). Business intelligence: A managerial approach ( $2^{\text {nd }}$ ed.). Upper Saddle River, NJ: Pearson Prentice Hall. 
22. Watson, H. J. (2008). Business schools need to change what they teach. Business Intelligence Journal, 13(4), 4-7.

23. Williams, S. (2011). 5 barriers to BI success and how to overcome them. Strategic Finance, 93(1), 27-33.

24. Wixom, B., Ariyachandra, T., Goul, M., Gray, P., Kulkarni, U., \& Phillips-Wren, G. (2011). The current state of business intelligence in academia. Communications of the Association for Information System, 29(16), 299-312.

25. Zhu, P., \& St. Amant, K. (2010). An application of Robert Gagné's nine events of instruction to the teaching of website localization. Journal of Technical Writing and Communication, 40(3), 337-362. 
NOTES 